\title{
CONSTITUCIONALIDAD DEL ESTATUTO DE ROMA Y REALIDAD JURÍDICO-POLÍTICA EN MÉXICO BAJO LA PERSPECTIVA DEL DERECHO COMPARADO
}

\section{Natalia CAÑIZ GARCÍA*}

RESUMEN: La autora parte de la problemática general acerca de la compatibilidad constitucional que se ha presentado en el derecho comparado en torno a la ratificación del Estatuto de Roma para realizar un análisis del caso mexicano. Las opciones que se han propuesto en México varían entre quienes abogan por la reforma constitucional y quienes niegan su necesidad, argumentando que es posible una interpretación armónica entre ambos textos. Situándose entre estos últimos, la autora analiza los diversos preceptos constitucionales que pudieran entrar en conflicto con el texto del Estatuto de la Corte Penal Internacional, y expone las razones por las que concluye que la reforma constitucional es necesaria.

ABSTRACT: The author begins by addressing the effects of the Rome Statute on constitutions of the States that ratified it. She then focuses on the Mexican case. Her analysis identifies two main currents to solve the problems existing between the Rome Statute and the Mexican Constitution. The first position considers that the Constitution has to be amended, while the second position argues that interpretation can be used to harmonize both texts. Her discussion reviews both positions and concludes holding that a constitutional reform is necessary.

RÉSUMÉ: Dans un premier temps, l'auteur étudie la problématique générale de la compatibilité constitutionnelle en droit comparé, conséquence de la ratification du Statut de Rome, pour analyser ensuite le cas mexicain. Au Mexique, il y a une pluralité d'opinions. Si certains spécialistes sont partisans d'une réforme constitutionnelle, d'autres sont contre une telle reforme, prétendant qu'il est possible de faire coexister la Constitution mexicaine et le Statut de Rome. L'auteur analyse les différents articles de la Constitution qui risquent d'entrer en conflit avec le Statut de la Cour Pénale Internationale et expose les raisons pour lesquelles une réforme de la Constitution mexicaine lui parait nécessaire.

* Amnistía Internacional México. 
SUMARIO: I. Introducción. II. El enfoque interpretativo. III. Disposiciones constitucionales presuntamente incompatibles con el Estatuto de Roma. IV. La solución propuesta para el caso de México.

\section{INTRODUCCIÓN}

La Corte Penal Internacional (CPI) ya es un hecho. El 11 de abril del 2002, 10 países ratificaron el Estatuto de Roma, sobrepasando las 60 ratificaciones necesarias para la entrada en vigor del mismo. El 1 de julio del 2002 el Estatuto de Roma entrará en vigor, y con él, por primera vez en el mundo, una Corte Penal Internacional de carácter permanente.

Sólo los Estados que han ratificado hasta el momento el estatuto - $\mathrm{y}$, previsiblemente, aquellos que lo hagan hasta el 1 de julio - formarán parte de la primera Asamblea de estados parte. En México la ratificación sigue siendo objeto de debate. Entre los partidarios del estatuto, la discusión se ha centrado desde un principio en la supuesta incompatibilidad del Estatuto de Roma con la Constitución mexicana, y la pertinencia o no de una reforma constitucional previa a la ratificación. Se señalaban tres posturas:

a) Reformar puntualmente los artículos constitucionales que presentaran un conflicto con la Constitución.

b) Hacer una reforma "paraguas" de un solo artículo, como en el caso francés.

c) Entender que las incompatibilidades son salvables realizando una interpretación armónica del estatuto y la Constitución.

Este debate - por otra parte - no se ha dado única y exclusivamente en México. Prácticamente en la totalidad de los países que han ratificado el estatuto o se encuentran en ese proceso, el tema ha sido objeto de amplias discusiones, no solamente en el ámbito gubernamental —con la creación de comisiones intersecretariales-, sino también en el académico y en el de la sociedad civil.

Ha habido aspectos comunes de eventual colisión entre las Constituciones nacionales y el Estatuto de la Corte Penal Internacional que se han planteado en un gran número de Estados. Me refiero al tema de las inmunidades, por ejemplo, a la aplicación del principio non bis in idem, o la duración de las penas. Sin embargo, los diversos procedimientos y fórmu- 
las empleados para superar los problemas señalados no siempre han sido los mismos. Ante idénticas dificultades se han arbitrado respuestas diferentes.

Las soluciones han sido de dos tipos: entender que es necesaria la reforma constitucional para garantizar la perfecta compatibilidad, o bien considerar que las eventuales fricciones son superables por la vía interpretativa.

\section{EL ENFOQUE INTERPRETATIVO}

¿En qué se basa el llamado enfoque interpretativo? ¿Cuál es la importancia de la interpretación constitucional? La Constitución es la norma fundamental que da validez a todo el ordenamiento jurídico. Validez material porque establece los principios y valores supremos de la comunidad política, su organización y estructura, y validez formal, ya que es el parámetro por el que se va a medir la nulidad o validez de las demás normas del ordenamiento. La trascendencia entonces de la interpretación constitucional es mucho mayor que la de cualquier otra norma.

La peculiaridad de las normas constitucionales se manifiesta también en su rigidez, que responde a la necesidad de garantizarles mayor permanencia y estabilidad en el tiempo. Pero también se corre el riesgo de que las normas se vuelvan desfasadas, obsoletas. Como ha señalado Limón Rojas: "Si el derecho constitucional es el marco jurídico del fenómeno político, debemos admitir que la capacidad de evolución de este fenómeno exige de la norma una especial capacidad de adaptación que la adecue constantemente a las nuevas exigencias". ${ }^{1}$

Ahora bien, ¿qué criterios seguir para interpretar la norma constitucional? Entre los estudiosos del tema son célebres las reglas de interpretación propuestas por Linares Quintana: ${ }^{2}$

No quedarse en una interpretación literal, y seguir un criterio teleológico o finalista. Hay que ir más allá de las palabras para descubrir la finalidad de la norma. Si perdemos de vista el sentido último de la norma, se puede volver perversa. Por ejemplo, en el tema de las inmunidades. Han sido tra-

1 Limón Rojas, M., "La interpretación constitucional”, Primer Congreso Nacional de Derecho Constitucional, Guadalajara, Jalisco, 1973, p. 73 (ponencia).

2 Linares Quintana, Tratado de la ciencia del derecho constitucional argentino y comparado, Buenos Aires, Alfa, 1953, t. II, pp. 469 y ss. 
dicionalmente concedidas por la gran mayoría de las Constituciones nacionales a ciertos actores estatales. Algunas la limitan a los actos parlamentarios, pero otras las extienden también a los procesos penales. ¿Cuál es el fundamento de estas inmunidades? Por razones de interés político se protege el cargo oficial del sujeto para evitar una interferencia indebida en el ejercicio de sus funciones, garantizando la independencia y equilibrio entre los poderes del Estado frente a una eventual extralimitación judicial. Pero si permitimos que un Jefe de Estado se ampare en esa inmunidad para evitar su responsabilidad por la comisión de un crimen internacional ¿no estamos desvirtuando la finalidad de la norma? Esta interpretación se mantiene ya desde Nuremberg y fue la mantenida por la Cámara de los Lores en el juicio contra Pinochet.

Hay que tener en cuenta el contexto político, social, económico, del momento en que se realiza la interpretación, que no va a ser el mismo que aquel en el que surge la Constitución.

Ha de ser un criterio amplio, liberal y práctico, nunca estrecho, limitado y técnico.

¿Cuál es la finalidad de toda Constitución? ¿No es también garantizar los derechos fundamentales de la persona, proteger la libertad y la dignidad humana. La Sala Constitucional de la Suprema Corte de Justicia de Costa Rica, respondiendo a una consulta sobre la constitucionalidad del Estatuto de Roma respondió que "la Constitución no se opone, al contrario, propone el desarrollo de este nuevo orden internacional de protección de los derechos humanos. Y si no se opone en general, tampoco lo hace ninguna de sus disposiciones en particular. Un sistema internacional de protección de los derechos del hombre, libremente consentido por los Estados, no puede considerarse, por razón de materia, contrario a una Constitución que se fundamenta en una concepción democrática del Estado.

¿Cuál sería la solución más aconsejable en el caso de México? ¿Podría realizarse una interpretación armónica entre la Constitución mexicana y el Estatuto de la Corte Penal Internacional que permitiese a México ratificarlo sin necesidad de reformar su Constitución?

\section{DISPOSICIONES CONSTITUCIONALES PRESUNTAMENTE INCOMPATIBLES CON EL ESTATUTO DE ROMA}

Se han señalado varias disposiciones del estatuto que podrían ser consideradas incompatibles con la Constitución mexicana: 


\section{Artículo 20. Cosa juzgada}

Este artículo establece excepciones al principio general de cosa juzgada al disponer en su párrafo tercero:

La corte no procesará a nadie que haya sido procesado por otro tribunal en razón de hechos también prohibidos en virtud de los artículos 6o., 7o. u 8o. a menos que el proceso en el otro tribunal:

a) Obedeciera al propósito de sustraer al acusado de su responsabilidad penal por crímenes de la competencia de la corte; o

b) No hubiere sido instruida en forma independiente o imparcial de conformidad con las debidas garantías procesales reconocidas por el derecho internacional o lo hubiere sido de alguna manera que, en las circunstancias del caso, fuere incompatible con la intención de someter a la persona a la acción de la justicia.

El estatuto proclama como principio general el non bis in idem. Sólo en el caso de que el proceso interno no haya cumplido con las garantías de debido proceso, o se haya tratado de un fraude procesal con el objeto de sustraer al acusado de su responsabilidad penal, la corte hace caso omiso del juicio celebrado en el Estado porque considera que la persona en realidad no fue juzgada.

Este artículo se presenta en contradicción con el artículo 23 de la Constitución, el cual recoge el consagrado principio penal de cosa juzgada o non bis in idem: la existencia de una sentencia anterior dictada en proceso seguido por los mismos hechos es causa de la extinción de la acción penal: "Artículo 23... Nadie puede ser juzgado dos veces por el mismo delito, ya sea que en el juicio se le absuelva o se le condene".

El Estatuto de Roma no ha sido el único en contemplar una excepción como la contenida en el artículo 20. Un supuesto similar lo encontramos ya en los Estatutos de los Tribunales Internacionales para la ex-Yugoslavia y Ruanda. ${ }^{3}$ Frente a tal previsión, que puede parecer un atentado a los principios más básicos del derecho penal, debemos preguntarnos qué se persigue con la inclusión de la misma. ¿No ha supuesto en ocasiones la excepción de cosa juzgada una auténtica burla a la administración de justicia?

La experiencia de los últimos años da buena muestra de ello. Leyes de autoamnistía, de punto final y de obediencia debida, el uso de la inmu- 
nidad por cargo oficial, la celebración de juicios simulados o plagados de vicios para exonerar de responsabilidad a los procesados han sido mecanismos utilizados en no pocas ocasiones. Y no hace falta remontarse a las dictaduras de los años setenta para encontrar algún ejemplo.

Los acusados de graves crímenes burlan la ley sirviéndose de la ley misma. Frente a sucesos de este tipo nada puede hacerse sin una previsión como la contenida en el estatuto.

Si en el derecho civil existe la figura de la simulación y fraude de ley, previéndose los efectos de nulidad o inexistencia para el caso de un negocio jurídico simulado, no se concibe que en derecho penal, donde se debaten bienes jurídicos aún más trascendentes, no exista una figura parecida que actúe en estas ocasiones.

En el comentario al artículo 42 del Proyecto de Código de Crímenes contra la Paz y la Seguridad de la Humanidad recogido en el Anuario de la Comisión de Derecho Internacional de 1994, ${ }^{4}$ relativo al non bis in idem, la CDI sostiene que debe asegurarse un mayor grado de protección frente al doble juzgamiento, y afirma que el aludido principio se aplica en dos casos:

- Cuando el acusado haya sido previamente juzgado por una Corte Penal Internacional y se plantee un juicio posterior ante otro tribunal.

- La situación inversa, de una persona juzgada previamente por otro tribunal y posteriormente acusada ante la corte por un crimen de los contemplados en el estatuto.

En el primer caso el principio es categórico, la sentencia — absolutoria o condenatoria - tendría carácter de definitiva, y el acusado no podría ser juzgado ante otro tribunal por el mismo crimen.

En el segundo supuesto, cuando el primer juzgamiento se realizase ante un tribunal nacional, el non bis in idem admitiría dos excepciones: que el acto en cuestión fuese calificado por el tribunal nacional como un delito ordinario y no como un crimen internacional competencia de la corte; y que el proceso ante el tribunal nacional careciera de independencia o imparcialidad o se hubiese celebrado con el propósito de sus-

4 Véase Yearbook of the International Law Comisión, 1994, Volume II, Part Two, Report of the Commission to the General Assembly on the work of its forty-sixth session. 
traer al acusado de su responsabilidad penal internacional, o bien el juicio no se hubiera celebrado con la debida diligencia.

La CDI mantiene que el principio de cosa juzgada no se extiende a crímenes de naturaleza distinta, a pesar de que puedan surgir de una misma situación de hecho. Por ejemplo, un acto aislado criminal, la muerte de un individuo puede ser calificado como homicidio o como genocidio si se comete con el ánimo específico de acabar con un grupo nacional, étnico, racial o religioso. La CDI emplea el concepto de delitos ordinarios para referirse a aquellas situaciones en las que un acto es calificado como delito común, distinto de un crimen internacional, aun teniendo las características peculiares que lo configuran como tal. Por ejemplo, un acto podría ser calificado como agresión en la legislación interna y como tortura o actos crueles según el derecho internacional.

La prohibición del non bis in idem no se aplicaría cuando el delito juzgado por el primer tribunal careciese en su definición o aplicación de aquellos elementos que lo configuran dentro de los crímenes competencia de la corte.

La CDI se ha referido también a la cuestión de la soberanía dual al considerar que el principio del non bis in idem es aplicable en el derecho interno, pero en derecho internacional no existe ninguna obligación para los Estados de reconocer una sentencia penal dictada en un Estado extranjero. ${ }^{5}$

En el sistema jurisdiccional mexicano se han dado excepciones al principio de cosa juzgada, como prueba la jurisprudencia al respecto:

NON BIS IN IDEM, CASOS EN QUE NO OPERA EL PRINCIPIO. La Constitución establece que nadie puede ser juzgado dos veces por el mismo delito, consagrando el antiguo principio non bis in idem; mas ello debe entenderse de acuerdo con el régimen federal marcado por la propia ley fundamental, la cual señala a los Estados miembros las facultades no conferidas en forma expresa a la Federación; por ende, la cosa juzgada sólo puede operar cuando se pronuncia por una entidad federativa, o por la autoridad judicial federal competente, una resolución irrevocable; pero si la sentencia definitiva dictada por un Estado adolece de nulidad, no existe impedimento alguno para que tribunales federales competentes, juzguen al inculpado. Ya esta Suprema Corte de Justicia ha expresado que si bien la Constitución previe-

5 Report of the International Law Commission on the work of its thirty-second session, 5 de mayo a 25 de julio de 1980 (A/35/10), Chapter II, Draft Code of Crimes against the peace and security of Mankind. 
ne que nadie puede ser juzgado dos veces por el mismo delito, esto se entiende cuando el primer juicio es válido y no anticonstitucional y nulo, ${ }^{6}$ porque en ese caso hay que volver las cosas al estado que guardaban antes de la violación constitucional, quedando expedita la jurisdicción del juez competente para hacer la reposición del proceso. ${ }^{7}$

Entendemos que un juicio contrario a la Constitución, y por tanto, inválido conforme a la sentencia referida, es aquel que no respeta las garantías procesales previstas en el artículo 20 constitucional, y aquellas otras que puedan ser ampliadas en virtud de instrumentos internos o internacionales.

\section{Artículo 27. Improcedencia del cargo oficial}

Dicho artículo dispone:

1. El presente Estatuto será aplicable por igual a todos sin distinción alguna basada en el cargo oficial. En particular, el cargo oficial de una persona, sea Jefe de Estado o de Gobierno, miembro de un Gobierno o Parlamento, representante elegido o funcionario de Gobierno, en ningún caso la eximirá de responsabilidad penal ni constituirá per se motivo para reducir la pena. 2. Las inmunidades y las normas de procedimiento especiales que conlleve el cargo oficial de una persona, con arreglo al derecho interno o al derecho internacional, no obstarán para que la corte ejerza su competencia sobre ella.

Las inmunidades han sido tradicionalmente concedidas por la gran mayoría de las Constituciones nacionales a ciertos actores estatales. Algunas limitan tal inmunidad a los actos parlamentarios, pero otras la extienden también a los procesos penales. ${ }^{8}$

6 Las cursivas son mías.

7 Semanario Judicial de la Federación, 6a. época, vol. LXI, 2a. parte, p. 33.

8 En la República Checa, los diputados y senadores disfrutan de la inmunidad parlamentaria, que sólo pierden en casos de que se compruebe que han cometido un delito grave. En Cuba, los diputados cuentan con inmunidad parlamentaria que puede ser retirada en caso de diversos delitos. Los parlamentarios británicos, elegidos todos por voto directo, gozan de derechos especiales que les otorgan protección para desarrollar su trabajo en la Cámara de los Comunes, pero frente a cargos criminales pueden ser arrestados y enfrentar un proceso judicial. En España, los legisladores cuentan con una inmunidad limitada, es decir, los protege en el desempeño de su cargo, pero no los exime de rendir cuentas ante los tribunales en el caso de cometer un delito. Sin embargo, para proceder judicialmente contra ellos se requiere de la autorización del congreso. Los integrantes del Congreso de Estados Unidos no pueden ser objeto de acción judicial por sus opiniones, pero no cuentan con ningún tipo de inmunidad en caso de cometer delitos. Fuentes: www.elpais.es y www.jornada.unam.mx. 
El fundamento de las inmunidades responde a un criterio funcional, según el cual, por razones de interés político se protege el cargo oficial del sujeto para garantizar la continuidad del servicio público y evitar una indebida interferencia en el ejercicio de sus funciones, garantizando la independencia y equilibrio entre los poderes del Estado frente a una eventual extralimitación judicial.

¿Qué dice la Constitución mexicana al respecto? El artículo 61 constitucional establece:

Artículo 61. Los Diputados y Senadores son inviolables por las opiniones que manifiesten en el desempeño de sus cargos y jamás podrán ser reconvenidos por ellas. El presidente de cada Cámara velará por el respeto al fuero constitucional de los miembros de la misma y por la inviolabilidad del recinto donde se reúnan a sesionar.

De la lectura de este artículo se desprende la distinción entre dos figuras diferentes: la inviolabilidad parlamentaria y el fuero constitucional.

La Suprema Corte de Justicia también se ha pronunciado al respecto:

INMUNIDAD PARLAMENTARIA Y FUERO CONSTITUCIONAL. SU APLICACIÓN CUANDO SE TRATA DE RESPONSABILIDAD PENAL Y DE RECLAMACIONES CIVILES QUE SE IMPUTAN A UN DIPUTADO FEDERAL. El artículo 61 de la Constitución Federal consagra la figura de la "inmunidad parlamentaria" como una garantía otorgada a los diputados federales y senadores, sólo por lo que hace a las opiniones que manifiesten en el desempeño de sus cargos, a grado tal que nunca podrán ser reconvenidos por ellas; mientras que el diverso artículo 111 de la propia Carta Magna, contempla la institución del "fuero constitucional", bajo la denominación actual de declaración de procedencia, como una garantía de carácter procesal, otorgada a diversos funcionarios públicos expresamente enunciados, entre ellos, los diputados y senadores. De ahí que, aunque son conceptos distintos, existe la posibilidad de que en materia penal se presente la conjugación de ambas figuras, precisamente en el caso de que un diputado federal atribuyera a una persona un hecho que puede ser constitutivo de delito, supuesto en el cual para proceder contra aquél, primeramente habría necesidad de hacer la declaración de procedencia prevista en el artículo 111 constitucional y después determinar si se está o no en el caso de la inmunidad a que se refiere el artículo 61 en cita. En cambio, si la imputación de ese hecho sólo puede generar afectación en derechos de orden civil del congresista, únicamente debe atenderse a la figura de la inmunidad sustantiva $y$, por ende, el fuero constitucional es totalmente ajeno; conclusión que se refuerza con el contenido del octavo 
párrafo del mencionado artículo 111, introducido mediante reforma publicada en el Diario Oficial de la Federación de veintiocho de diciembre de mil novecientos ochenta y dos, sin mayor virtud que la de refrendar con ánimo clarificador lo ya dicho en el primer párrafo de ese numeral a propósito de la necesidad de declaración de procedencia en materia penal. Esto es si en el primer párrafo se estableció desde el origen de la actual Ley Fundamental, que ese requisito era necesario en materia penal, obligado era deducir que no abarcaba a la materia civil; pero conforme al octavo párrafo, del artículo 111 referido, desecha cualquier resquicio de que también rige para la materia civil, pues categóricamente y sin ambages así lo declara. En consecuencia, si la reclamación jurisdiccional que se endereza contra un diputado federal es de índole civil, exclusivamente debe ponderarse el fuero-inmunidad a que se refiere el artículo 61 constitucional, sin tomar en consideración el fuero de procedibilidad consagrado en el artículo 111 constitucional; lo que no implica que exista impedimento para demandarlo en la vía civil por actos que realice como particular, ajenos a su encargo o al quehacer parlamentario. ${ }^{9}$

El título cuarto de la Constitución, que comprende los artículos 108 a 115, lleva por encabezado De las responsabilidades de los servidores públicos.

La fracción II del artículo 109 dispone que "la comisión de delitos por cualquier servidor público será perseguida y sancionada en términos de la legislación penal", pero el precepto 111 enumera a determinados funcionarios que únicamente pueden ser procesados penalmente previo pronunciamiento al respecto de la Cámara de Diputados. ${ }^{10}$

Con base en lo establecido en el título cuarto de la Constitución, Fernando Castellanos ha señalado que la responsabilidad opera de modo diferente según la categoría funcionarial de que se trate: ${ }^{11}$

Primera categoría. Estaría integrada por diputados y senadores al Congreso de la Unión, los ministros de la Suprema Corte de Justicia de la Nación, los consejeros de la Judicatura Federal, los secretarios de Despacho, los jefes de Departamento Administrativo, los representantes a la

9 Semanario Judicial de la Federación, 9a. época, t. XII, 1a. sala, diciembre de 2000. Tesis: 1a. XXVII/2000, p. 248, Materia constitucional. Tesis aislada.

10 Por medio del decreto de 28 de diciembre de 1982 se reformaron varios artículos constitucionales, sustituyendo el término fuero constitucional por el de declaración de procedencia. Sin embargo, el término se mantiene en el artículo 61 de la Constitución y en los artículos 11 y 12 de la Ley Orgánica del Congreso General de los Estados Unidos Mexicanos, de 31 de agosto de 1999.

11 Castellanos, F., Lineamientos elementales del derecho penal, México, Porrúa, 1997, pp. 112 y ss. 
Asamblea del Distrito Federal, el jefe de gobierno capitalino, el procurador general de la república y el procurador general de justicia del Distrito Federal.

Para exigir responsabilidad penal a los funcionarios mencionados, la Cámara de Diputados, por mayoría absoluta de los miembros presentes, debe declarar si ha lugar o no a proceder en contra del inculpado; si la declaración es afirmativa, el funcionario es separado de su cargo pasando a disposición judicial. Si el proceso penal correspondiente finalizase con sentencia absolutoria, el inculpado podrá reasumir su cargo. Si la declaración de la Cámara de Diputados fue negativa, se suspenderá cualquier procedimiento, pero ello no será obstáculo para que se reanude cuando el inculpado finalice el ejercicio de su cargo. ${ }^{12}$

Segunda categoría. La constituyen los gobernadores de los Estados, diputados locales y magistrados de los Tribunales Superiores de Justicia de los Estados, y en su caso, los miembros de los Consejos de las Judicaturas Locales.

Respecto a estos funcionarios, se sigue el mismo procedimiento señalado para los de primera categoría, con la salvedad de que la declaratoria de procedencia sólo produce el efecto de que se comunique a las legislaturas locales, para que procedan como corresponda en el ejercicio de sus atribuciones. Las Constituciones estatales establecerán en su caso el procedimiento a seguir, acorde a los lineamientos generales establecidos en la norma fundamental.

Tercera categoría. Únicamente incluye al presidente de la república, quien durante el tiempo de su cargo sólo puede ser acusado por traición a la patria y por delitos graves del orden común. ${ }^{13}$

El artículo 111 de la Constitución señala que el presidente únicamente podrá ser acusado ante la Cámara de Senadores en los términos del artículo 110 (juicio político). El Senado resolverá con base en la legislación penal aplicable, previa acusación de la Cámara de Diputados.

Desde el proceso de Nuremberg se produjo una ruptura con la doctrina tradicional al no admitirse como eximentes la obediencia debida ni la inmunidad de la que gozaban los jefes de Estado. ${ }^{14}$ Las cartas de los Tribunales de Nuremberg y Tokio, los Estatutos de los Tribunales para la ex-

12 Artículo 111 constitucional.

13 Artículo 108 constitucional, segundo párrafo. Cfr. artículo 194 del Código Federal de Procedimientos Penales.

14 Véase supra II. 
Yugoslavia ${ }^{15}$ y Ruanda y el Estatuto de Roma han confirmado claramente que los tribunales tienen competencia respecto de los acusados de delitos graves de derecho internacional independientemente del cargo o posición oficial que ocuparan en el momento del crimen o posteriormente.

La cuestión de las inmunidades se ha debatido prácticamente en todos los países. En España, el Consejo de Estado español dictaminó que, en lo referente a la inviolabilidad del rey:

Se fundamenta en su posición, ajena a toda controversia, dado el carácter debido de sus actos en el modelo constitucional de 1978... En suma, la irresponsabilidad personal del Monarca no se concibe sin su consecuencia esencial, esto es, la responsabilidad de quien refrenda y que, por ello, es el que incurriría en la eventual "responsabilidad penal individual" a que se refiere el artículo 25 del estatuto.

Y continúa:

La interpretación esbozada, cimentada sobre categorías dogmáticas acuñadas en el derecho constitucional comparado por referencia al régimen parlamentario más intenso y, en particular, a la forma política de las Monarquías Parlamentarias... no ha de representar una fractura de los propósitos y fines del Estatuto de Roma ni de los términos en que define la competencia de la CPI sino una aplicación plena de aquél con respecto de las variadas concepciones políticas vigentes en los que serán sus Estados Partes. ${ }^{16}$

En el juicio contra Pinochet en Inglaterra, la Cámara de los Lores dictaminó que la tortura no forma parte de las funciones de un jefe de Estado, y por tanto no procede la inmunidad por actos de tortura cometidos durante el ejercicio del cargo.

¿Cómo resolver con base en una interpretación armónica la cuestión de las inmunidades? El artículo 27 del estatuto no impone a los Estados la obligación de eliminar en el ámbito interno las inmunidades y fueros de las personas señaladas, regula únicamente la actividad procesal ante la corte.

15 El artículo 7.2 del ETIY dispone "La categoría oficial de un acusado, ya sea como Jefe de Estado o de Gobierno, o como alto funcionario, no le exonera de su responsabilidad penal y no es motivo de disminución de la pena".

16 Dictamen del Consejo de Estado, núm. de expediente 1.374/99, Madrid, 22 de julio de 1999. 
Por otra parte, debemos considerar que la existencia de la CPI no estaba prevista en el momento de redactar las disposiciones constitucionales. El derecho internacional ha avanzado mucho desde entonces. Los Estados han reconocido, mediante la ratificación de otros tratados internacionales que lo establecen claramente, el deber de enjuiciar o extraditar a una persona, sin tomar en cuenta el cargo oficial del acusado. Inmunidad no es sinónimo de impunidad.

Así, México es parte de la Convención para la Prevención y Castigo del Delito de Genocidio, ${ }^{17}$ cuyo artículo 4o. establece que "Las personas que hayan cometido genocidio o cualquiera de los otros actos enumerados en el artículo III, serán castigadas, ya se trate de gobernantes, funcionarios o particulares". Por tanto, el supuesto que contempla el estatuto en materia de inmunidades no es ninguna novedad y ya fue aceptado por México.

\section{Artículo 29. Imprescriptibilidad}

Señala este artículo que: "Los crímenes de la competencia de la corte no prescribirán".

Se ha considerado que este artículo podría ser violatorio de las garantías individuales del procesado contempladas en el artículo 20 de la Constitución, pero lo cierto es que la prescripción de los delitos no es una garantía que se recoja de modo expreso en el texto constitucional. Además, cabe mencionar que en enero pasado, el Senado mexicano aprobó, entre otros instrumentos internacionales, la Convención sobre la Imprescriptibilidad de los Crímenes de Guerra y de Lesa Humanidad, la cual establece en su artículo IV la obligación para los Estados partes de:

Adoptar, con arreglo a sus respectivos procedimientos constitucionales, las medidas legislativas o de otra índole que fueran necesarias para que la prescripción de la acción penal o de la pena, establecida por ley o de otro modo, no se aplique a los crímenes mencionados en los artículos I y II de la presente Convención y, en caso de que exista, sea abolida.

Por lo tanto, es presumible que la próxima ratificación por parte del ejecutivo mexicano de la citada Convención venga precedida de las reformas penales pertinentes, con lo cual el problema se solventaría.

17 Adoptada en Nueva York el 9 de diciembre de 1948, vinculante para México desde su ratificación el 22 de julio de 1952. 


\section{Artículo 54. Funciones y atribuciones del fiscal}

con respecto a las investigaciones

El estatuto señala que corresponde al fiscal, no a los Estados ni al Consejo de Seguridad, decidir la apertura de una investigación, y basándose en el resultado de ésta, iniciar el enjuiciamiento previa autorización de la Sala de Cuestiones Preliminares.

Para ello, cuenta con amplias facultades, entre otras, reunir y examinar pruebas; hacer comparecer e interrogar a las personas objeto de investigación, las víctimas y los testigos; solicitar la cooperación de un Estado u organización, y adoptar o pedir que se adopten las medidas necesarias para asegurar el carácter confidencial de la información, la protección de una persona o la preservación de las pruebas.

Por su parte, el artículo 21 constitucional otorga el monopolio de la acción penal al Ministerio Público, y de la imposición de las penas al Poder Judicial. "Artículo 21. La imposición de las penas es propia y exclusiva de la autoridad judicial. La investigación y persecución de los delitos incumbe al Ministerio Público".

En este artículo precisamente se ubica la reforma propuesta por la cancillería, que será objeto de análisis con posterioridad.

\section{Artículo 67. Derechos del acusado}

Este artículo enumera los derechos del acusado incluyendo las garantías mínimas durante el proceso.

Se ha apuntado un posible conflicto con el artículo 13 de la Constitución, el cual señala que "nadie puede ser juzgado por leyes privativas ni por tribunales especiales".

La Suprema Corte de Justicia ha interpretado el concepto de tribunal especial y de ley privativa.

TRIBUNALES ESPECIALES. Por tribunales especiales se entiende aquellos que se crean exclusivamente para conocer, en un tiempo dado, de ciertos delitos o respecto de determinados delincuentes; por tanto, no puede considerarse tribunal especial, al juez que se nombre para auxiliar a otro en el despacho de todos los negocios de su competencia. ${ }^{18}$ 
Entendemos que la Corte Penal Internacional no entra bajo este concepto, ya que precisamente se caracterizará por su permanencia y pretensión de universalidad, por lo cual no habría conflicto con el precepto constitucional mencionado. La discusión queda abierta en el caso de los tribunales creados por el Consejo de Seguridad, que sí responden al significado de tribunales especiales, por su temporalidad y carácter ad hoc.

\section{Artículo 72. Protección de información que afecte a la seguridad nacional}

Dicho artículo "será aplicable en todos los casos en que la divulgación de información o documentos de un Estado pueda, a juicio de éste, afectar a los intereses de su seguridad". ${ }^{19}$

Así lo establece el mismo artículo en su párrafo cuarto cuando señala que "Si un Estado tiene conocimiento de que información o documentos suyos están siendo divulgados o pueden serlo en cualquier fase del procedimiento y estima que esa divulgación afectaría a sus intereses de seguridad nacional, tendrá derecho a pedir que la cuestión se resuelva de conformidad con el presente artículo". La protección de información es, por tanto, un derecho que opera sólo a petición del Estado.

Es importante mencionar que, en la adopción de las medidas necesarias para resolver la cuestión del tratamiento de la información, participarán el fiscal, la defensa y la Sala de Cuestiones Preliminares o la Sala de Primera Instancia según el caso. ${ }^{20}$

Las medidas que el estatuto contempla para que la información del Estado no sea divulgada y por tanto no se ponga en riesgo la seguridad nacional van desde una modificación o aclaración de la solicitud, la obtención de la información o las pruebas de una fuente distinta o en una forma diferente, hasta lograr un acuerdo sobre las condiciones en que se preste la asistencia que incluya, entre otras cosas, la presentación de resúmenes o exposiciones, restricciones a la divulgación, la utilización de procedimientos a puerta cerrada o ex parte, u otras medidas de protección permitidas con arreglo al estatuto. ${ }^{21}$

En resumen, la decisión de que la divulgación de información o documentos de un Estado puede presentar un riesgo para su seguridad nacio- 
nal es una decisión que compete al propio Estado, y por tanto él es el único habilitado para solicitar ante la corte que se proteja dicha información.

En segundo lugar, se requiere llegar a un acuerdo entre el Estado afectado, el fiscal, la defensa y la Sala de Cuestiones Preliminares o de Primera Instancia para determinar el trato que recibirá la información.

Si el Estado, no conforme con las medidas que se acuerden, decide que la divulgación de esa información atenta su seguridad nacional, podrá solicitar a la corte celebrar consultas a puerta cerrada y ex parte para exponer sus razones.

La persistencia del Estado en su negativa a cooperar con la corte facultará a la misma para remitir la cuestión a la Asamblea de los Estados Partes o al Consejo de Seguridad, si éste le hubiese remitido el asunto. ${ }^{22}$

Finalmente, si la corte decide que la información es pertinente y necesaria para determinar la culpabilidad o la inocencia del acusado, podrá ordenar la divulgación de la información o en su defecto establecer las presunciones pertinentes respecto al acusado según las circunstancias. ${ }^{23}$

El derecho de los acusados de hacerse de todos los medios de prueba para organizar su debida defensa únicamente podría verse menoscabado si existiera un acto de Estado solicitando la protección de ciertas pruebas cuya divulgación represente ser sensible a su seguridad nacional. En tal supuesto, la defensa participaría en la determinación de la manera en que dicha información sería tratada y si el Estado definitivamente negase el acceso de la información y aquella fuese necesaria y pertinente para determinar la inocencia o culpabilidad del acusado, la corte establecerá las presunciones a favor de la culpabilidad o inocencia del acusado con base en la información disponible.

Se ha apuntado que este artículo podría atentar contra las garantías de debido proceso contenidas en los artículos 14 y 20 de la Constitución mexicana. Especial mención merece la fracción VII del artículo 20, el cual, refiriéndose a las garantías procesales del inculpado, señala: "Le serán facilitados todos los datos que solicite para su defensa y que consten en el proceso".

Como José Antonio Guevara ha señalado, sería conveniente que el Estado mexicano regulase en el plano interno el tratamiento dado a la información que afecte a la seguridad nacional, estableciendo criterios cla- 
ros acerca de qué se entiende por seguridad nacional y cuáles son los límites dentro de los cuales se maneja la clasificación de dicha información. ${ }^{24}$

\section{Artículo 77. Penas aplicables}

1. La corte podrá, con sujeción a lo dispuesto en el artículo 110, imponer a la persona declarada culpable de uno de los crímenes a que se hace referencia en el artículo 5 del presente Estatuto una de las penas siguientes:

b) la reclusión a perpetuidad cuando lo justifiquen la extrema gravedad del crimen y las circunstancias personales del condenado.

La Constitución mexicana no prohíbe expresamente la cadena perpetua, pero establece al respecto: “Artículo 22. Quedan prohibidas las penas de mutilación y de infamia, la marca, los azotes, los palos, el tormento de cualquier especie, la multa excesiva, la confiscación de bienes y cualesquiera otras penas inusitadas y trascendentales".

La jurisprudencia de la Suprema Corte de Justicia ha interpretado que la cadena perpetua se encuentra englobada bajo la categoría de "penas inusitadas".

PENAS INUSITADAS. Salta a la vista que la pena de cadena perpetua es inusitada, atenta nuestras leyes vigentes y aun las anteriores, de carácter penal, y por lo mismo, de las prohibidas por el artículo 22 constitucional. La simple prisión perpetua o la de trabajos forzados, sin encadenar perpetuamente al sentenciado, deben ser consideradas como penas inusitadas, dentro del criterio jurídico de nuestra Constitución y de nuestro sistema penal, sin que obste la circunstancia de que la prisión perpetua, sin cadena, no se haya proscrito aún del sistema penal de algunos países civilizados, pues basta que sean estas penas de las prohibidas por el artículo 22 constitucional, para que el extranjero que esté expuesto a sufrir alguna de ellas, por la extradición que pida su país, deba gozar de la protección que el artículo 10. de nuestra Constitución, concede a todo individuo, sea mexicano o extranjero. $^{25}$ 
Nos sorprende sin embargo que se considere inusitada la cadena perpetua y no la pena de muerte, vigente conforme al último párrafo del mencionado artículo constitucional para ciertos delitos:

Artículo $22 \ldots$ Queda también prohibida la pena de muerte por delitos políticos, y en cuanto a los demás, sólo podrá imponerse al traidor a la Patria en guerra extranjera, al parricida, al homicida con alevosía, premeditación o ventaja, al incendiario, al plagiario, al salteador de caminos, al pirata y a los reos de delitos graves del orden militar.

\section{Del artículo 24 del Código Penal del Distrito Federal se desprende} que la pena capital ha sido excluida del catálogo legal; lo mismo se advierte en los códigos locales de los Estados de la Federación. Sin embargo, el que no haya sido prohibida constitucionalmente mantiene la posibilidad de su aplicación, como ha señalado la Suprema Corte de Justicia:

PENA DE MUERTE, PROCEDENCIA DE LA. Independientemente del debate que se suscita entre abolicionistas y partidarios de la pena de muerte, y de los argumentos que algunos autores han expuesto en torno de la posible trascendencia de dicha sanción, en tanto que en el artículo 22 constitucional se autoriza la pena de muerte para el homicidio con alevosía, premeditación o ventaja, esto es, para el autor del delito de homicidio calificado, resulta ineficaz cualquiera argumentación contra el registro de la pena de muerte en algunos códigos punitivos de la República y de la aplicación de la misma por parte del órgano jurisdiccional, pues aún en el supuesto de que desde el punto de vista teórico se alegara la ineficacia o trascendencia de la pena capital, permitida por el legislador constitucional, queda plenariamente legitimada en los casos consignados por la Carta Magna. ${ }^{26}$

En Latinoamérica, varias Constituciones prohíben la pena de reclusión perpetua expresamente, como la salvadoreña, ${ }^{27}$ la venezolana, ${ }^{28}$ la colombiana, ${ }^{29}$ la hondureña ${ }^{30}$ la nicaragüense ${ }^{31}$ o la uruguaya ${ }^{32}$

La Convención de Roma dispone de modo expreso que se imponga esta pena cuando lo justifiquen la extrema gravedad del crimen y las cir- 
cunstancias personales del condenado. ${ }^{33}$ Por tanto, no va a ser la regla general sino la excepción.

El artículo 77 del estatuto se remite además al 110, el cual obliga a la corte a un proceso de revisión de la pena para "determinar si ésta puede reducirse" una vez que el condenado haya cumplido 25 años de prisión. Hay que tener presente, por otra parte, que el propio estatuto enumera los principios y normas de derecho internacional como fuente del derecho aplicable por la corte. ${ }^{34}$ Dentro de esas normas se encuentra el Pacto Internacional de Derechos Civiles y Políticos, el cual dispone que la finalidad esencial del régimen penitenciario será la reforma y la readaptación social de los penados. ${ }^{35}$

Si la corte, en su revisión inicial, decide no reducir la pena, se llevarán a cabo audiencias adicionales en las cuales la corte tomará en cuenta criterios relacionados con la conducta, rehabilitación y otras circunstancias del condenado. ${ }^{36}$ Por lo cual pensamos que tampoco habría colisión con la disposición del artículo 18 constitucional que señala que el sistema penal estará orientado a la readaptación social del delincuente. ${ }^{37}$

Hay que destacar además que el estatuto establece en su artículo 80, que "nada de lo dispuesto... se entenderá en perjuicio de la aplicación por los Estados de las penas prescritas por su legislación nacional”. Esto quiere decir que en ninguna circunstancia se forzará a un Estado a que ejecute una sentencia vitalicia acordada por la corte; un Estado parte puede imponer condiciones a cualquier acuerdo sobre el cumplimiento de penas en su territorio. Así lo determina el estatuto cuando señala que "en el momento de declarar que está dispuesto a recibir condenados, el Estado podrá imponer condiciones a reserva de que sean aceptadas por la corte y estén en conformidad con la presente parte". ${ }^{38}$

Por lo tanto, con base enl régimen de complementariedad de la corte, si el Estado investiga o enjuicia tales crímenes, la corte cederá paso a la acusación por parte del Estado al margen de que éste no contemple imponer cadena perpetua. 


\section{Artículo 102. Entrega de ciudadanos a la corte}

El artículo 102 del estatuto hace una importante distinción entre dos términos, señalando que:

a) Por "entrega" se entenderá la entrega de una persona por un Estado a la corte de conformidad con lo dispuesto en el presente estatuto;

b) Por "extradición" se entenderá la entrega de una persona por un Estado a otro Estado de conformidad con lo dispuesto en un tratado o convención o en el derecho interno.

La distinción no es en absoluto banal, ya que dependiendo de que se trate de una figura o de otra se aplicará un régimen jurídico diferente: la entrega se regirá por las disposiciones del estatuto mientras que la extradición seguirá lo dispuesto en el tratado o convención internacional correspondiente y en las normas de derecho interno de cada país. Por tanto no debemos confundir ambos términos aunque a primera vista parezcan semejantes. ${ }^{39}$

La Constitución mexicana no contempla la figura de la entrega pero si la de la extradición, al señalar:

Artículo 15. No se autoriza la celebración de tratados para la extradición de reos políticos, ni para la de aquellos delincuentes del orden común que hayan tenido en el país donde cometieron el delito, la condición de esclavos; ni de convenios o tratados en virtud de los que se alteren las garantías y derechos establecidos por esta Constitución para el hombre y el ciudadano.

Por su parte el artículo 119 constitucional dispone en su último párrafo:

Las extradiciones a requerimiento de Estado extranjero serán tramitadas por el Ejecutivo Federal, con la intervención de la autoridad judicial en los términos de esta Constitución, los Tratados Internacionales que al respecto se suscriban y las leyes reglamentarias. En estos casos, el auto del juez que mande cumplir la requisitoria será bastante para motivar la detención hasta por sesenta días naturales.

39 Cfr. la Ley de Extradición mexicana, la cual usa indistintamente los términos de entrega (artículos 1o., 5o. y 14) y extradición (artículos 2o., 3o. y 6o.). 
Algunas Constituciones latinoamericanas prohíben la extradición de ciudadanos nacionales. ${ }^{40}$ No es el caso de la mexicana, pero aún así insistimos de nuevo en la importancia de la diferencia terminológica. ${ }^{41}$

Teniendo presente que la CPI no podrá juzgar en rebeldía, para que el juicio se lleve a cabo, la corte debe asegurar la comparecencia física del acusado, por lo que la obligación de los países de cooperar con la corte en la detención y entrega de personas a la corte se convierte en un instrumento fundamental. Esa obligación se presupone con más fuerza al considerar que los propios Estados participaron en el proceso de creación de la corte y en la elaboración de sus estatutos.

Consideramos por tanto que este artículo no supondría un problema por las razones que se han expuesto acerca de la diferencia conceptual. No se concibe un buen funcionamiento de la corte sin la cooperación de los Estados con la misma, y en ese sentido la entrega de sospechosos es un aspecto decisivo.

\section{LA SOLUCIÓN PROPUESTA PARA EL CASO DE MÉXICO}

Tras un análisis de cada uno de los preceptos constitucionales y del estatuto que se han señalado como presuntamente incompatibles, insistiendo siempre en la interpretación teleológica de cada precepto; un estudio de la jurisprudencia interna aplicable a cada caso y tomando como referencia el derecho comparado de países que optaron también por la vía de la interpretación ${ }^{42}$ ¿cuáles fueron las conclusiones?

40 Por ejemplo, la Constitución nicaragüense (artículo 43). La Constitución costarricense aún va más allá al establecer que "ningún ciudadano costarricense puede ser obligado a abandonar el territorio nacional". En estos casos, la incompatibilidad se resolvería si el Estado de la nacionalidad iniciase la investigación pertinente, evitando así la solicitud de entrega de la corte.

41 La Ley de Extradición internacional de 29 de diciembre de 1975 en su artículo 14 dispone que "ningún mexicano podrá ser entregado a un Estado extranjero sino en casos excepcionales a juicio del ejecutivo". Se trata de un prohibición general que admite excepciones, como lo muestran los numerosos casos de extradición a EUA de ciudadanos mexicanos. Para mayor información sobre la extradición de nacionales y el proceso de extradición en México véanse: Labardini, Rodrigo, "México y la extradición de nacionales", Anuario Mexicano de Derecho Internacional, México, UNAM, Instituto de Investigaciones Jurídicas, vol. II, 2002, y Gómez-Robledo Verduzco, Alonso, Extradición en derecho internacional, México, UNAM, Instituto de Investigaciones Jurídicas, 2001.

42 En España, concretamente, también se discutió la constitucionalidad del Tratado de Roma y la pertinencia o no de la reforma constitucional. Se pidió un dictamen preceptivo, pero no vinculante, al Consejo de Estado, el máximo órgano consultivo del gobierno, quien estudió los preceptos constitucionales que podrían colisionar con el estatuto y dictaminó que no era necesaria una reforma. 
La semejanza de algunos preceptos con los que se discutían en México parecía apoyar la misma solución. ¿Sería posible, por tanto, realizar una interpretación armónica entre la Constitución mexicana y el Estatuto de la Corte Penal Internacional, que permitiese a México ratificarlo sin necesidad de reformar su Constitución?

Tras pasar más de un año inmersa en el ambiente político que rodeaba y rodea el tema, acudiendo a actos, conferencias y seminarios, conociendo la opinión de expertos mexicanos en la materia, la autora de este artículo llegó a la conclusión de que en el caso de México sí es necesaria la reforma constitucional. ¿Por qué? ¿Por qué lo que funciona para un país en otro no? ¿Por qué no son válidas soluciones similares ante problemas similares? Porque en cada caso se dan presupuestos y condicionantes jurídicos y políticos diferentes.

Entre los jurídicos, por ejemplo:

a) La rigidez o la flexibilidad constitucional. La Constitución española ha sufrido una única reforma en 24 años, con motivo de la entrada en la CEE. Aunque teóricamente se la califica como rígida, la Constitución mexicana ha sufrido más de 400 reformas en 85 años, esto supone una media de casi cinco reformas anuales. Ha habido artículos que se han modificado 6,8 y hasta 15 veces, en ocasiones. Por lo tanto, si hay cualquier indicio de incompatibilidad constitucional, se va a optar, sin duda, por la reforma. ${ }^{43}$

b) ¿Cuál es el sistema de recepción del derecho internacional en el ámbito interno y que lugar se reconoce al derecho internacional en la jerarquía normativa? El lugar del derecho internacional en el ordenamiento jurídico mexicano, en mi opinión, no está claro.

Por una parte, la Constitución establece que los tratados internacionales celebrados por el Ejecutivo y que estén de acuerdo con la Constitución son ley suprema de la unión. Pero no establece un orden jerárquico, ese orden lo ha establecido la doctrina y la jurisprudencia. La jurisprudencia venía manejando que el criterio de que los tratados internacionales estaban al mismo nivel de las leyes federales, y desde el 99 los sitúa directamente por debajo de la Constitución y en un plano superior a las le-

43 Es mucho más rígido el procedimiento de reforma previsto en la Constitución española: hay límites que establecen que no se puede proceder a la reforma en tiempo de guerra o de Estado de sitio, alarma o excepción. Se prevé la posibilidad de que la reforma sea sometida a referéndum si así lo solicita la décima parte de los miembros de cualquiera de las cámaras dentro de los 15 días siguientes a la aprobación, por no hablar de si la reforma afecta a la parte de los derechos fundamentales y libertades públicas, a la organización del Estado o a la Corona. 
yes. Creo que un tema tan importante como ese no se debe dejar en manos de la jurisprudencia. Debería reformarse el artículo 133 constitucional para dejar ya de un lado las interpretaciones y establecer claramente la jerarquía de los tratados en el orden interno.

En México se vive una curiosa paradoja: es un país donde hay muchas leyes pero en la práctica no se aplican o no se cumplen. Y además se las reforma constantemente. Aparte de las reformas constitucionales que comentaba, el Código Penal del D. F., por poner un ejemplo, sufrió 83 reformas de septiembre del 99 a julio del 2000, que representan en promedio una modificación cada cuatro días. Esto genera una gran incertidumbre jurídica e inestabilidad.

¿Qué lugar ocupa el derecho internacional en este panorama? La práctica demuestra que el derecho internacional no se aplica, porque entre los jueces generalmente se ignora tanto el contenido del derecho internacional como su funcionamiento. ${ }^{44} \mathrm{Y}$ en materia de derechos humanos no es una excepción. Iura novit curia: el juez tiene el deber de conocer el derecho. Y en el caso de México, el derecho no es sólo la Constitución, no son sólo las leyes federales y estatales, son también los tratados internacionales ratificados por México.

México es parte en 58 instrumentos internacionales de derechos humanos, y el número se va a ampliar, porque recientemente el Senado aprobó otro paquete. Pero no tiene sentido ratificar tantos instrumentos si en la práctica no se aplican. En eso consiste el Estado de derecho: tener las leyes necesarias y la certeza jurídica de que esas leyes se cumplen.

El procedimiento de reforma constitucional no distingue un procedimiento más agravado en el caso, por ejemplo, de que la reforma afectase al capítulo dedicado a las garantías individuales, es el mismo, independientemente del artículo constitucional que se quiera reformar. Se requiere que la reforma sea aprobada por una mayoría de dos tercios del

44 Me llamaba la atención la sentencia de 1994, del juez primero de distrito en el estado de Nuevo León, en la que, ante el cuestionamiento de si el secretario de relaciones exteriores está facultado para firmar tratados internacionales, el juez, con base en la Constitución, afirmó que "sólo el Presidente de la República está facultado constitucionalmente para obligar al país y por tanto, para celebrar tratados internacionales". Esta sentencia desconoce totalmente tanto la práctica como el derecho internacional, ya que la CV69, de la que México forma parte, establece que los ministros de asuntos exteriores gozan de la presunción de ser representantes de Estado, y en consecuencia no requieren de representación de plenos poderes para participar en la celebración de tratados internacionales. 
congreso y posteriormente por la mayoría (la mitad más uno) de los congresos estatales de la república. ${ }^{45}$

c) ¿Cuál es el concepto de soberanía que se tiene en un país o en otro, y cómo se refleja constitucionalmente? Aquí de nuevo las diferencias son notables. En México, por su pasado histórico, hay un rechazo total de entrada a todo lo que pueda implicar una posible cesión de soberanía, se ve como algo pernicioso en sí.

En la Constitución española hay un artículo (93) que establece que mediante LO (sic) se podrá autorizar la celebración de tratados por los que se atribuya a una organización o institución internacional el ejercicio de competencias derivadas de la Constitución. La Ley Fundamental de Bonn, en Alemania, tiene un artículo similar. ¿En qué estaba pensando el constituyente de 1978 cuando introdujo este precepto? Sin duda, en la eventual adhesión de España a las CCEE. El proceso de integración en la Unión Europea ha sido un éxito porque los Estados han ido cediendo competencias, primero en el ámbito económico, luego, cada vez más, en el político. No me parece tan importante la cesión de soberanía, sino los objetivos que se buscan con ella.

La propuesta inicial de reforma constitucional sugerida por la cancillería mexicana iba en el sentido de reconocer constitucionalmente la competencia de los tribunales internacionales establecidos en tratados en los que México sea parte, de acuerdo con los procedimientos especificados en los tratados correspondientes. Sin embargo, nos parece conveniente hacer referencia expresa en la reforma al Estatuto de Roma, dada la trascendencia de este instrumento y para no dejar en manos de la jurisprudencia futuras situaciones que se puedan plantear.

¿Por qué ubicar la reforma en el artículo 21 de la Constitución? El reconocimiento que se propone de estas jurisdicciones nacionales está encaminado a fortalecer la protección de los derechos humanos, conlleva un régimen que complementa y adiciona aquel que se contiene en las garantías individuales consagradas en el capítulo I de la Constitución. En este artículo se establece que corresponde al Ministerio Público el ejercicio de la acción penal, por tanto es el artículo idóneo para prever una posible cesión de competencias cuando se requiera de una intervención de la CPI.

45 Artículo 135: La presente Constitución puede ser adicionada o reformada. Para que las adiciones o reformas lleguen a ser parte de la misma, se requiere que el Congreso de la Unión, por el voto de las dos terceras partes de los individuos presentes, acuerde las reformas o adiciones, y que éstas sean aprobadas por la mayoría de las legislaturas de los Estados. 
Hemos visto algunos condicionantes de tipo jurídico. En el orden político, ¿qué factores influyen?, ¿cuál fue la posición de México desde el principio con respecto al estatuto?

Aunque la SRE expresó públicamente su apoyo en la creación de la Corte Penal Internacional, México no votó a favor del estatuto en la Conferencia de Roma, tampoco votó en contra, se abstuvo. Por tanto, el texto final del estatuto no fue para México tan satisfactorio como esperaba.

Entre las objeciones de México al estatuto se encontraron, por ejemplo, la relación entre la corte y el Consejo de Seguridad, la no inclusión de las armas de destrucción masiva (químicas, bacteriológicas, nucleares) como crímenes de guerra, la cláusula del artículo 124, o la posibilidad de ampliar la competencia a otros crímenes. ¿Cuál es la probabilidad de que un conflicto Constitución-Estatuto de Roma llegue a plantearse realmente?

México tiene un pasado de graves violaciones a los derechos humanos, casos de tortura, detenciones arbitrarias, ejecuciones extrajudiciales, desapariciones, casos de abuso y privación de justicia. No hay que remontarse muchos meses atrás para recordar el asesinato de una defensora de derechos humanos en esta misma ciudad. La mayoría de los casos quedan sin resolver, sigue prevaleciendo la impunidad. Son casos graves, pero desde luego, no de gravedad suficiente como para ser objeto de competencia de la corte. La corte no va a enjuiciar hechos aislados.

Si un Estado tiene plena confianza en la labor de sus instituciones y en la eficacia del Poder Judicial, no se plantea la posibilidad de que un crimen de los recogidos en el estatuto cometido bajo su jurisdicción sea llevado ante la corte.

¿Hay realmente una voluntad política de ratificar el estatuto? ¿Hay un grado de consenso entre las fuerzas políticas - y la opinión públicaen cuanto a la conveniencia de ser parte en el tratado?

En México no hay una conciencia entre los legisladores de la importancia de aprobar este instrumento jurídico. En el ámbito político y en el militar hay quienes no ven con buenos ojos la ratificación de este instrumento porque argumentan que supone un ataque para la soberanía de México. Sigue habiendo un conservadurismo muy fuerte, que se explica en parte por el pasado histórico de México. Pero la soberanía implica el poder del Estado, incluso para autolimitarse.

Lo cierto es, aunque la CPI se articula en torno al principio de complementariedad respecto de las jurisdicciones nacionales, implica en última instancia la cesión — cuando concurran las circunstancias que pre- 
vé- de determinadas potestades y funciones actualmente ligadas a la soberanía de los Estados.

La decisión sin precedentes de la administración de George W. Bush de revocar la firma del estatuto hecha por la anterior administración estadounidense es preocupante, pero no debe menoscabar todo el proceso de entrada en vigor de la corte. Confiamos por tanto en que el Ejecutivo mexicano no se deje presionar en este tema y adopte la decisión de ratificar por los intereses del país, tanto en el ámbito interno como en el internacional. 